\title{
Hepatocellular Carcinoma-Associated Polymyositis Presenting With Unilateral Upper Limb Subcutaneous Edema
}

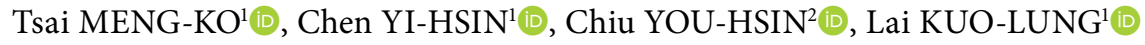 \\ ${ }^{1}$ Department of Internal Medicine, Taichung Veterans General Hospital, Taichung, Taiwan \\ ${ }^{2}$ Department of Radiology, Taichung Veterans General Hospital, Taichung, Taiwan
}

\begin{abstract}
Localized subcutaneous edema is a rare manifestation of inflammatory myopathy. In general, the incidence of malignancy in dermatomyositis (DM) is higher than that in polymyositis (PM). The association between malignancy and DM has been established; however, it is less convincing in PM. In this article, we report on a case of malignancy-associated PM with an initial presentation of localized subcutaneous edema. A 66-year-old male patient with a history of chronic hepatitis B was presented to us with both left arm swelling and progressive proximal muscle weakness. A multi-detector row computed tomography showed prominent left arm edema, while a venography demonstrated no venous thrombosis or stenosis. A diagnosis of PM was established according to its typical symptoms, high serum creatine kinase level, positive electromyography findings, and systemic inflammatory signs. Magnetic resonance imaging of the liver revealed infiltrative hepatocellular carcinoma (HCC). After undergoing systemic corticosteroid therapy, in combination with hydroxychloroquine, the left arm edema was resolved. However, patient died from HCC three months after the date of diagnosis. It is important to recognize that HCC-associated PM may initially present itself with localized non-pitting edema. Although such localized edema may be responsive to corticosteroids, a patient's overall prognosis remains poor. We presume that PM with localized subcutaneous edema may be a predictor of malignancy, and therefore recommend a tumor survey.

Keywords: Edema; malignancy; polymyositis.
\end{abstract}

Inflammatory myopathy is characterized by proximal muscle weakness which is highly suspected through an autoimmune pathogenesis. Extramuscular manifestations including fever, arthralgia, and pulmonary complications are common. ${ }^{1}$ Diagnosis of both polymyositis (PM) and dermatomyositis (DM) relies on characteristic clinical manifestations, increased serum muscle enzymes, and a standard electromyography (EMG). Periorbital edema is often accompanied by a heliotrope rash. ${ }^{1}$ However, subcutaneous edema in limbs is extremely rare. A literature search uncovered 33 cases of limb edema associated with inflammatory myopathy, of whom seven were localized edema, while the remaining were considered generalized edema. All seven patients with localized edema were diagnosed with DM. In this article, we report on a case of PM with localized subcutaneous edema and hepatocellular carcinoma (HCC). To the best of our knowledge, this is the first case of localized edema to be associated with PM.

\section{CASE REPORT}

A 66-year-old male patient was admitted to our medical center having experienced progressive

Received: October 22, 2017 Accepted: January 09, 2018 Published online: January 29, 2018

Correspondence: Lai Kuo-lung, MD. Department of Internal Medicine, Taichung Veterans General Hospital, 407 Taichung, Taiwan. Tel: 04-23934191\#12 e-mail: kllaichiayi@vghtc.gov.tw 

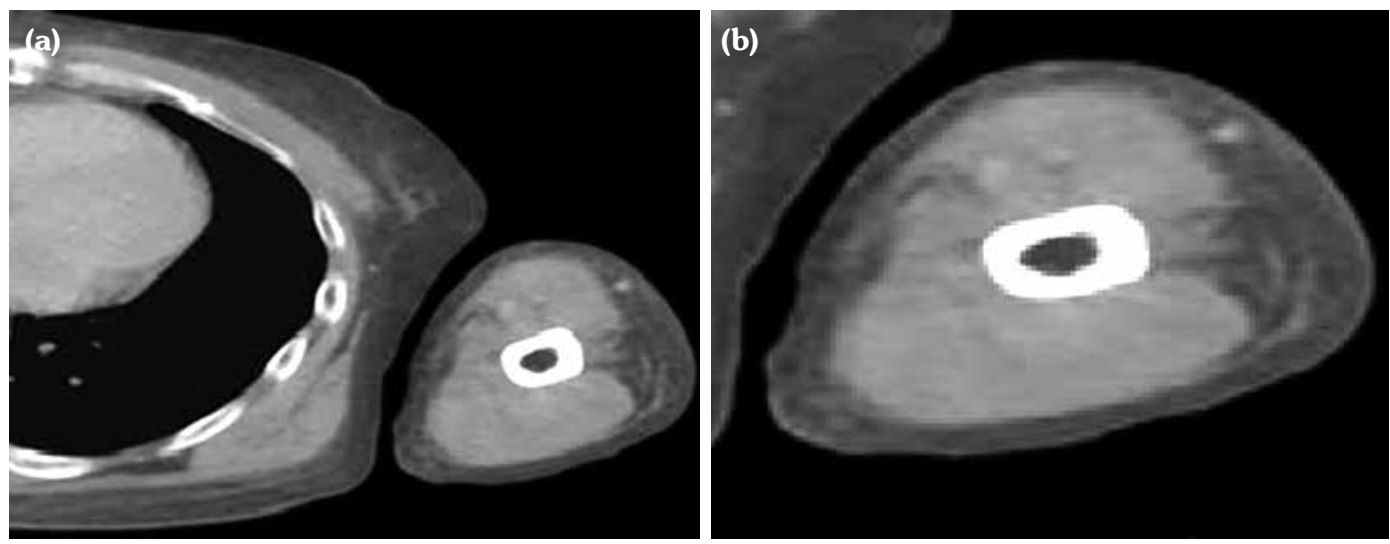

Figure 1. (a) Multi-detector row computed tomography demonstrates subcutaneous edema of left arm without any obvious soft tissue edema of chest wall. (b) Prominent subcutaneous edema of left arm without thickened fascia or swollen muscle.

proximal symmetric muscle weakness and myalgia for six weeks, along with left arm swelling and pain for three weeks. He was a hepatitis $\mathrm{B}$ virus (HBV) carrier without any regular follow-ups. Otherwise, he displayed no human immunodeficiency virus infection, alcohol abuse or recent illegal drug administration. Upon arrival, his vital signs were stable without showing any cardiopulmonary distress. A physical examination demonstrated prominent non-pitting edema at his left arm and forearm without any signs of redness, warmth, or tenderness. No palpable neck or axillary lymphadenopathy was found. A neurological examination resulted in a muscle power score of four in the thighs and arms. The patient's sensation was intact and the deep tendon reflexes were normal. There was no typical rash resulting from DM or signs of Raynaud phenomenon. Laboratory values included $\mathrm{C}$-reactive protein at $1.1 \mathrm{mg} / \mathrm{dL}$, creatine kinase $(\mathrm{CK})$ level of $4,325 \mathrm{U} / \mathrm{L}$, lactate dehydrogenase of $446 \mathrm{U} / \mathrm{L}$, and aspartate aminotransferase of $231 \mathrm{~g} / \mathrm{dL}$. Thyroid function, renal test results, and electrolyte levels were within normal limits. The antinuclear antibody titer was 1:80, displaying a fine speckled pattern (positive $\geq 1: 160$ ). The anti-Jo-1 antibody was negative. The electromyographic findings showed abnormal electrical irritability and short duration consistent with inflammatory myopathy. A nailfold capillary microscope revealed avascular zones and enlarged loops which supported the diagnosis of PM. This retrospective case study was approved by our Institution Review Board (protocol number: CE17124B).

Multi-detector row computed tomography showed prominent subcutaneous edema at the left upper arm and forearm (Figure 1). No venous thrombosis or stenosis was noted
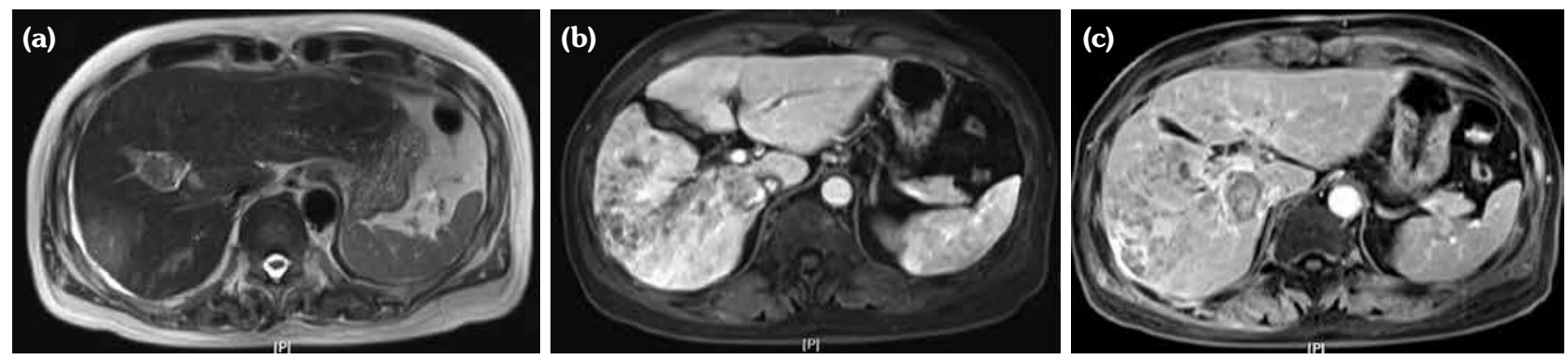

Figure 2. (a) A magnetic resonance imaging of liver. Multiple nodules and mass occupied at right lobe of liver, with more on S5 and S6. High signals evident in $\mathrm{T}_{2}$-weighted image. (b) A magnetic resonance imaging of liver. Heterogeneous low signals in $\mathrm{T}_{1}$-weighted image, with mild and heterogeneous enhancement in arterial phase. (c) A magnetic resonance imaging of liver with a mild wash-out pattern in venous phase. Stenosis of right main portal vein with internal soft tissue signal. These image findings confirm diagnosis of infiltrative hepatocellular carcinoma. 
during a venography. The patient had active hepatitis $B$ with reactive hepatitis $B$ surface antigen and HBV viral load of $244,000 \mathrm{IU} / \mathrm{mL}$. High alpha-fetal protein $(960 \mathrm{ng} / \mathrm{mL})$ was noted. The malignancy survey identified infiltrative HCC through magnetic resonance imaging of the liver (Figure 2). The patient was treated with baraclude for HBV and sorafenib for HCC.

The patient's left upper limb edema gradually improved through the use of intravenous dexamethasone at a dose of $5 \mathrm{mg}$ twice daily (equivalent to $0.7 \mathrm{mg} / \mathrm{kg} / \mathrm{day}$ of prednisolone). This was followed by an oral dose of methylprednisolone at $16 \mathrm{mg}$ per day (equivalent to $0.3 \mathrm{mg} / \mathrm{kg} /$ day of prednisolone). The patient's muscle weakness also improved, and he experienced a continuous decrease in his blood CK level (866 U/L on day 13). Hydroxychloroquine $400 \mathrm{mg}$ per day was administered for immunomodulation. The patient was discharged on the $13^{\text {th }}$ day of his hospital stay. During the two-month outpatient follow-up period, no recurrence of left upper limb edema was noted, although mild fluctuations in muscle power and blood CK level were noted. He died on HCC three months after the date of diagnosis.

\section{DISCUSSION}

This case involved PM with HCC, along with localized subcutaneous non-pitting edema in the left arm. The clinical, laboratory, and EMG evaluations were all compatible with $\mathrm{PM}$. We researched the causes of both pitting and nonpitting edema (e.g., hypothyroidism, renal failure, congestive heart failure, liver cirrhosis, and deep vein thrombosis) but all were unremarkable. The patient's localized non-pitting edema was recovered through treatment using systemic corticosteroid and hydroxychloroquine.

Bohan and Peter criteria ${ }^{2}$ have been the most widely-used classification criteria for inflammatory myopathies over the past decades; however, several limitations have created difficulties in their interpretation. Tanimoto et al. $^{3}$ proposed a new classification criteria which included eight items: (1) proximal muscle weakness, (2) elevated serum CK or aldolase levels, (3) muscle pain on grasping or spontaneous pain, (4) myogenic changes on EMG, (5) positive anti-Jo-1 antibodies, (6) nondestructive arthritis or arthralgias, (7) systemic inflammatory signs, and (8) pathological findings compatible with inflammatory myositis. When a patient meets at least four of these items, other than skin lesion items, he or she shall be classified as having PM. Our patient met the items of $1,2,3,4$, and 7 , therefore PM was diagnosed. A muscle biopsy is a simple procedure; however, it may lead to some complications such as bruising, prolonged bleeding, or wound infection. Since prominent subcutaneous edema may result in poor wound healing, ${ }^{4}$ a muscle biopsy was not performed on our patient.

Subcutaneous edema is a very rare clinical presentation of inflammatory myopathy. To our knowledge, our case is the first to document localized edema associated with PM. We performed a review of the literature using the MEDLINE [PubMed], and included case reports, series and reviews. The search terms used included "dermatomyositis", "polymyositis", and "edema". We located 33 relevant articles published between 1982 and 2016. ${ }^{5-26}$ Information regarding age, distribution of edema, malignancy, treatment modality, along with responses extracted from the above articles and our case, was outlined in Table 1.

The mean age was 54.8 years (range 23-93). Nineteen patients (55.9\%) were female. Eight patients (23.5\%) experienced localized subcutaneous edema while 26 patients (76.5\%) had generalized subcutaneous edema. Six patients (17.6\%) were associated with PM, and 28 patients (79.4\%) were associated with $\mathrm{DM}$. The subcutaneous edema recovered spontaneously in two cases, and through corticosteroid treatment in seven cases. ${ }^{2,4,5,11,13,20,23}$ Immunosuppressants for these patients included azathioprine, methotrexate, cyclophosphamide, or mycophenolate mofetil $(n=9)$ and tacrolimus $(n=2)$. Thirteen cases received intravenous immunoglobulin. 7,10,14-18,21,22 Our case received the medium dose of corticosteroid in adjunction with hydroxychloroquine, and the clinical response in resolving localized edema was good.

In general, the incidence of malignancy in $\mathrm{DM}$ was higher than that in PM. The association between malignancy and DM was established; however, it is less convincing in PM. A nationwide 
Table 1. Literature review of inflammatory myopathy and subcutaneous edema

\begin{tabular}{|c|c|c|c|c|c|c|c|}
\hline $\begin{array}{c}\text { Case } \\
\text { no }\end{array}$ & Diagnosis & $\begin{array}{l}\text { Age (year)/ } \\
\text { Sex }\end{array}$ & $\begin{array}{l}\text { Distribution of } \\
\text { edema }\end{array}$ & Malignancy & Treatment modality & Response & Reference \\
\hline 1 & PM & 73/M & Generalized & NA & $\mathrm{Pd}, \mathrm{AZA}$ & Death & 2 \\
\hline 2 & PM & $32 / \mathrm{M}$ & Generalized & NA & $\mathrm{Pd}$ & Resolution & 2 \\
\hline 3 & PM & $52 / \mathrm{M}$ & Generalized & NA & $\mathrm{Pd}, \mathrm{AZA}$ & Death & 2 \\
\hline 4 & PM & $65 / \mathrm{M}$ & Generalized & NA & Observation & Resolution & 3 \\
\hline 5 & DM & $62 / \mathrm{F}$ & Generalized & - & $\mathrm{Pd}$ & Resolution & 4 \\
\hline 6 & PM & $56 / \mathrm{M}$ & Generalized & - & $\mathrm{Pd}$ & Resolution & 5 \\
\hline 7 & DM & $27 / F$ & Localized & - & $\mathrm{Pd}, \mathrm{AZA}$ & Resolution & 6 \\
\hline 8 & DM & $31 / \mathrm{M}$ & Generalized & - & Pd, hydrocortisone, IVIG & Resolution & 7 \\
\hline 9 & DM & $63 / \mathrm{M}$ & Localized & - & Observation & Resolution & 7 \\
\hline 10 & $\mathrm{DM}$ & $54 / \mathrm{M}$ & Localized & - & MPL, MTX & Resolution & 8 \\
\hline 11 & $\mathrm{DM}$ & $78 / \mathrm{F}$ & Localized & - & Pd, MTX & Resolution & 9 \\
\hline 12 & DM & $40 / \mathrm{M}$ & Generalized & - & Pd, IVIG & Death & 10 \\
\hline 13 & DM & $78 / F$ & Generalized & - & $\mathrm{Pd}$ & Resolution & 11 \\
\hline 14 & DM & $29 / F$ & Generalized & NA & Pd, MPL, CYC & Death & 12 \\
\hline 15 & DM & $55 / F$ & Localized & Breast cancer 6 years ago & $\mathrm{Pd}$ & Resolution & 13 \\
\hline 16 & $\mathrm{DM}$ & $48 / \mathrm{F}$ & Generalized & - & MPL, MTX, IVIG & Resolution & 14 \\
\hline 17 & $\mathrm{DM}$ & $61 / \mathrm{F}$ & Generalized & Cervical tumor on PET & Pd, AZA, MMF, IVIG & Resolution & 15 \\
\hline 18 & DM & $62 / \mathrm{M}$ & Generalized & NA & Pd, MTX & Resolution & 16 \\
\hline 19 & DM & $23 / \mathrm{F}$ & Generalized & NA & Pd, MTX, IVIG & Resolution & 16 \\
\hline 20 & $\mathrm{DM}$ & $38 / \mathrm{F}$ & Generalized & NA & Pd, MTX, IVIG & Resolution & 16 \\
\hline 21 & $\mathrm{DM}$ & $38 / \mathrm{M}$ & Localized & NA & MTX, IVIG & Resolution & 16 \\
\hline 22 & DM & $52 / \mathrm{F}$ & Generalized & - & Pd, MTX, AZA, CYC, IVIG & Resolution & 17 \\
\hline 23 & DM & $38 / \mathrm{M}$ & Generalized & - & $\begin{array}{l}\text { Pd, hydrocortisone, MTX, } \\
\text { IVIG }\end{array}$ & Resolution & 18 \\
\hline 24 & DM & $57 / \mathrm{F}$ & Generalized & NA & MPL & Death & 19 \\
\hline 25 & DM & $44 / \mathrm{F}$ & Generalized & - & Pd, MPL & Resolution & 20 \\
\hline 26 & $\mathrm{DM}$ & $47 / \mathrm{F}$ & Generalized & - & $\begin{array}{l}\text { Pd, MPL, AZA, IVIG, } \\
\text { tacrolimus }\end{array}$ & Resolution & 21 \\
\hline 27 & DM & $72 / \mathrm{F}$ & Generalized & Colon cancer 3 years ago & Pd, IVIG & Death & 22 \\
\hline 28 & DM & $73 / \mathrm{M}$ & Localized & $\begin{array}{l}\text { Urothelial carcinoma and } \\
\text { prostate adenocarcinoma } \\
\text { in the past }\end{array}$ & Pd, AZA, IVIG & Resolution & 22 \\
\hline 29 & $\mathrm{DM}$ & $47 / \mathrm{F}$ & Generalized & - & $\mathrm{Pd}, \mathrm{AZA}$ & Resolution & 22 \\
\hline 30 & $\mathrm{DM}$ & $80 / \mathrm{F}$ & Generalized & $\begin{array}{l}\text { Endometrial carcinoma in } \\
\text { the past }\end{array}$ & $\mathrm{Pd}, \mathrm{AZA}$ & Resolution & 22 \\
\hline 31 & $\mathrm{DM}$ & $93 / F$ & Generalized & Gastric tumor on PET-CT & Pd, MPL, IVIG & Death & 22 \\
\hline 32 & $\mathrm{DM}$ & $67 / F$ & Generalized & NA & $\mathrm{Pd}$ & Resolution & 23 \\
\hline 33 & DM & $62 / \mathrm{M}$ & Generalized & NA & Pd, Tacrolimus & Resolution & 23 \\
\hline 34 & PM & $66 / \mathrm{M}$ & Localized & HCC on MRI & $\begin{array}{l}\text { Intravenous dexamethasone, } \\
\text { MPL, hydroxych-loroquine }\end{array}$ & Resolution & $\begin{array}{l}\text { Our } \\
\text { patient }\end{array}$ \\
\hline
\end{tabular}


cohortstudy of the relationship between malignancy and inflammatory myopathy in Taiwan showed an incidence of $4.4 \%$ in $\mathrm{PM}$ and $9.4 \%$ in DM. ${ }^{27}$ As for our review, the prevalence of malignancy in PM- and DM-associated subcutaneous edema was $50 \%(1 / 2)$ and $10 \%(2 / 20)$, respectively. The recognition of malignancy could be either through tissue pathology or imaging. Twelve cases were without mention of tumor survey, while four with a past malignancy without recurrence were excluded from the analysis. There is a considerable risk of malignancy in patients with both inflammatory myopathy and subcutaneous edema; therefore, a comprehensive tumor survey is recommended.

The pathophysiology of edema has been well documented, and includes Starling forces, change in capillary permeability, reduction of effective arterial volume, renal factors, and the renin-angiotensin-aldosterone system, along with natriuretic peptides. However, the mechanism of subcutaneous edema for inflammatory myositis remains unclear. Lymphatic blockage has been proposed as the cause of severe edema. ${ }^{22}$ Another possible cause is widespread active vasculitis. ${ }^{15}$ Most patients with cancer-associated dermatomyositis display antibodies to the nuclear matrix protein-2 (NXP-2). ${ }^{28}$ Rogers et al. ${ }^{29}$ demonstrated a novel relationship between the NXP-2 antibody and peripheral edema in adult DM patients. However, the cause of peripheral edema in DM patients remains unclear, and thus requires further investigation.

\section{Declaration of conflicting interests}

The authors declared no conflicts of interest with respect to the authorship and/or publication of this article.

\section{Funding}

The authors received no financial support for the research and/or authorship of this article.

\section{REFERENCES}

1. Dalakas MC. Inflammatory muscle diseases. N Engl J Med 2015;372:1734-47.

2. Bohan A, Peter JB. Polymyositis and dermatomyositis (first of two parts). N Engl J Med 1975;292:344-7.

3. Tanimoto K, Nakano K, Kano S, Mori S, Ueki $\mathrm{H}$, Nishitani $\mathrm{H}$, et al. Classification criteria for polymyositis and dermatomyositis. J Rheumatol 1995;22:668-74.
4. Thomas Hess C. Checklist for factors affecting wound healing. Adv Skin Wound Care 2011;24:192.

5. Venables GS, Bates D, Cartlidge NE, Hudgson P. Acute polymyositis with subcutaneous oedema. J Neurol Sci 1982;55:161-4.

6. Lyon-Caen O, Bouche P, Chaunu MP, Duyckaerts $\mathrm{C}$, Vitoux JF. Acute polymyositis with spontaneously regressive subcutaneous edema. Apropos of a case. Rev Neurol (Paris) 1985;141:749-52.

7. Nitsche A, San Agustín PG, Amado V, Prina AP, Corsaro G. Trunk and abdominal wall edema in dermatomyositis. Medicina (B Aires) 1988;48:331-2.

8. Andonopoulos AP, Gogos CA, Tzanakakis G. Subcutaneous edema: an "unrecognized" feature of acute polymyositis. Rheumatol Int 1993;13:159-61.

9. Smyth AE, Bell AL, Crone M. Acute oedematous dermatomyositis. Ann Rheum Dis 2000;59:575.

10. Gorelik O, Almoznino-Sarafian D, Alon I, Rapoport MJ, Goltsman G, Herbert M, et al. Acute inflammatory myopathy with severe subcutaneous edema, a new variant? Report of two cases and review of the literature. Rheumatol Int 2001;20:163-6.

11. Thurairajah P, Browne S, Bondeson J. A painful swollen calf. J R Soc Med 2003;96:236-7.

12. Mroué KH, Sharara NH, Rbeiz JG, Arayssi TK. A case of edematous dermatomyositis. J Rheumatol 2003;30:2722-3.

13. Werner de Castro GR, Appenzeller S, Bértolo MB, Costallat LT. Acute dermatomyositis with subcutaneous generalized edema. Clin Rheumatol 2006;25:898-900.

14. Ito Y, Kawabata D, Yukawa N, Yoshifuji H, Usui T, Tanaka M, et al. Severe subcutaneous generalized edema in a patient with dermatomyositis. Mod Rheumatol 2007;17:171-3.

15. Dunkley L, Jawad ASM. Subcutaneous oedema as a presenting feature of polymyositis/dermatomyositis: a poor prognostic indicator? Grand Rounds 2007;7:21-5.

16. Rafailidis PI, Kapaskelis A, Falagas ME. Periorbital and facial swelling due to dermatomyositis. CMAJ 2007;176:1580-1.

17. Lee KH, Lim SR, Kim YJ, Lee KJ, Myung DS, Jeong $\mathrm{HC}$, et al. Acute dermatomyositis associated with generalized subcutaneous edema. Rheumatol Int 2008;28:797-800.

18. Haroon M, Eltahir A, Harney S. Generalized subcutaneous edema as a rare manifestation of dermatomyositis: clinical lesson from a rare feature. $\mathrm{J}$ Clin Rheumatol 2011;17:135-7.

19. Chai Y, Bertorini TE, Li YD, Mitchell C, Guan H. Limb edema and anasarca associated with severe dermatomyositis: report of four cases. Neuromuscul Disord 2011;21:439-42.

20. Jung KD, Kim PS, Park HY, Kim CR, Byun JY, Lee DY, et al. Dermatomyositis associated with generalized subcutaneous edema and Evans syndrome. J Am Acad Dermatol 2012;66:144-7. 
21. Tu J, McLean-Tooke A, Junckerstorff R. Increasing recognition of dermatomyositis with subcutaneous edema - is this a poorer prognostic marker? Dermatol Online J 2014;20:21244.

22. Sherzai D, Rao R, Nguyen C, Schulz E, Sherzai A. Lymphatic blockage and severe edema in dermatomyositis: lessons from this case and others. Case Reports in Clinical Pathology 2014;1:12-6.

23. Peng ACY, Huang CH, Lin TS, Lee JYY. Severe dermatomyositis with pronounced generalized subcutaneous edema and dysphagia: A rare manifestation of a highly active disease. Dermatologica Sinica 2014;32:97-100.

24. Jin Ur, Kwack K-S, Park K-J, Kwon J-E, Kim $\mathrm{S}-\mathrm{Y}$, Kim K-C, et al. Acute polymyositis/systemic lupus erythematosus overlap syndrome with severe subcutaneous edema and interstitial lung disease. J Rheum Dis 2014;21:25-9.

25. Milisenda JC, Doti PI, Prieto-González S, Grau JM. Dermatomyositis presenting with severe subcutaneous edema: five additional cases and review of the literature. Semin Arthritis Rheum 2014;44:228-33.

26. Watanabe M, Natsuga K, Arita K, Abe R, Shimizu $\mathrm{H}$. Generalized acute subcutaneous edema as a rare cutaneous manifestation of severe dermatomyositis. J Eur Acad Dermatol Venereol 2016;30:151-2.

27. Chen YJ, Wu CY, Huang YL, Wang CB, Shen JL, Chang YT. Cancer risks of dermatomyositis and polymyositis: a nationwide cohort study in Taiwan. Arthritis Res Ther 2010;12:70.

28. Fiorentino DF, Chung LS, Christopher-Stine L, Zaba L, Li S, Mammen AL, et al. Most patients with cancerassociated dermatomyositis have antibodies to nuclear matrix protein NXP-2 or transcription intermediary factor $1 \gamma$. Arthritis Rheum 2013;65:2954-62.

29. Rogers A, Chung L, Li S, Casciola-Rosen L, Fiorentino DF. Cutaneous and Systemic Findings Associated With Nuclear Matrix Protein 2 Antibodies in Adult Dermatomyositis Patients. Arthritis Care Res (Hoboken) 2017;69:1909-14. 